\title{
Methicillin-resistant Staphylococcus aureus (MRSA) Isolated from
}

\section{Colombian Foods}

María Consuelo Vanegas López ${ }^{\mathrm{x}}$, Jaime Enrique Moreno ${ }^{2}$, Viviana Ramos Rueda ${ }^{2}$, Juan Sebastián Chirivi ${ }^{1}$, Angélica Garzón $^{1}$, Stefany Alejandra Arévalo ${ }^{1}$, María Fernanda Martínez ${ }^{1}$, Paula Andrea Gardeazábal ${ }^{1}$ and Cristian Baquero

${ }^{1}$ Laboratorio de Ecología Microbiana y de Alimentos (LEMA), Departamento de Ciencias Biológicas Universidad de los Andes, Cra 1 \#18A-10 J401, Bogotá D.C., Colombia.

${ }^{2}$ National Health Institute (INS), laboratory of Microbiology, Cll 26 No 51-20, Bogotá D.C., Colombia.

doi:10.5618/bio.2012.v2.n1.6 || Received: 29-05-2012, Accepted: 12-07-2012, Available online: 16-07-2012

\section{Abstract}

Methicillin-resistant Staphylococcus aureus (MRSA) was identified as a nosocomial pathogen in the 1960s and it is associated with serious community-acquired and nosocomial diseases, particularly in immunocompromised patients. $S$. aureus also causes food poisoning and is the most important food-borne disease in Latin America. In Colombia, the Community acquired (CA-MRSA) increased by 4.4\% between 2001 and 2006. However, the transmission of MRSA through food has not been well researched; its prevalence is unknown as is the risk of consumer exposure. It is important to determine the role of food in transmission of antibiotic-resistant bacteria, taking into account that the prevalence of MRSA varies according to geographical location. The aim of this study was to determine the prevalence of MRSA in Colombian foods and to typify isolated strains by detecting antimicrobial resistance, clonal groups and Toxin $A$ gene. Resistance of $149 \mathrm{~S}$. aureus strains isolated from food was determined by disk diffusion with oxacillin $(1 \mu \mathrm{g})$ and cefoxitin $(30 \mu \mathrm{g})$, Antimicrobial Susceptibility Test (AST) and mecA gene amplification. Positive strains were genotyped using pulsed field electrophoresis (PFGE). 5 (3.35\%) of the 149 strains resistant to oxacillin and cefoxitin, were positive to mecA gene, indicating the presence of the SCC cassette. The electrophoretic pattern obtained by PFGE for these strains revealed that $4(80 \%)$ of the 5 strains belong to the Chilean clone, with $100 \%$ genetic similarity; this clone has been associated with $65 \%$ of infections associated with health care. Furthermore, none of the 5 strains were positive to Toxin $A$ gene. This is the first evidence of the presence of MRSA in food in Colombia. It is necessary to continue this research by extending the sampling and collecting enough information to carry out risk analysis of the danger.

Keywords: Methicillin-resistant; Staphylococcus aureus; PCR; Antibiotic resistant.

\section{Introduction}

Staphylococcus aureus is considered the third most important cause of disease in the world among reported foodborne illnesses [1]. In the early 1960s, the first strain Staphylococcus aureus methicillin-resistant (MRSA) was described in the United Kingdom (UK), immediately after the introduction of methicillin into clinical practice [2]. This microorganism has emerged as a major public health concern worldwide because of its differential ability to spread and cause hospital-based and community outbreaks [3].

In the United States, during 1992-2003, the number of health care associated infections due to MRSA increased from $35.9 \%$ to $64.4 \%$ and in UK, death certificates increased by 39\% [4]. In Colombia, the CA-MRSA (community-acquired, or communityassociated Staphylococcus aureus) increased from $1 \%$ in 2001 to $5.4 \%$ in 2006 [5].

While environmental MRSA transmission has been investigated, transmission through food products has not received enough attention [1, 6]. However, Normmano et al established the presence of $S$. aureus strains that harboured the mecA gene isolated from food samples such as bovine milk, mozzarella cheese, and pecorino cheese [1]. Beside the available information reported, the current prevalence of resistant bacteria in food matrices and levels of MRSA consumer exposure risks remain unknown. 
Nowadays the assessment of the activity of an antibiotic is crucial to the successful outcome of antimicrobial therapy; however the development of resistance both in human and animal bacterial pathogens has been associated with the extensive therapeutic use of antimicrobials or with their administration as growth promoters in meat product production $[6,7]$.

Recently, some investigators have suggested that bacteria may act as reservoirs of antibiotic resistant genes. Because of this, it is important to carry out studies to establish the role played by this microorganism in horizontal transfer of antibiotic resistant genes to intestinal microorganisms and food associated pathogenic bacteria [8]. These resistant bacteria may be transferred from meat product sources to humans by various means, such as the food supply (cattle, chickens, pigs and turkeys); this anti-microbial resistance results in human health consequences [9].

The major mechanism of resistance to $\beta$-lactam antibiotics is due to the acquisition of the mecA gene, which is located in the staphylococcal chromosome cassette, mec (SCC). The gene product of mecA is a penicillin-binding protein (PBP), designated PBP2a [10-12] that can function as a transpeptidase [13].

Besides methicillin resistance, MRSA strains are important in safe food because they are able to produce a variety of extracellular products as coagulase Staphylococcal enterotoxins (SEs) such as the classic enterotoxins SEB, SEC, SED, SEE and SEA [14]. SEA and SED are the most common enterotoxins associated with food poisoning outbreaks [15].

In order to achieve the detection of resistance of Staphylococcus aureus strains, various techniques have been described, such as the employment of a cefoxitin $30 \mu \mathrm{g}$ disc, using semiconfluent inoculums and overnight incubation at $35^{\circ} \mathrm{C}$, resulting in a sensitivity of $100 \%$ and a specificity of $99 \%$. In this way, disc diffusion remains the method of choice for routine screening for methicillin resistance in microbiological laboratories and is complemented by the mecA detection by PCR [16].

On the other hand, one of the most widely used molecular typing methods for the study of local epidemiology of MRSA is pulsed field gel electrophoresis (PFGE). This method has been used to identify MRSA clones that have a particular ability to cause major outbreaks [17, 18].

S. aureus isolated from nutritional matrices such as meat and dairy products were tested for MRSA using the disk diffusion test. MRSA strains were also genotyped and amplify by PCR in order to confirm the presence of the mecA and Toxin A genes and detect clonal groups.

\section{Materials and Methods}

Samples of food such as meat products, vegetables, milk and milk derivatives were evaluated for contamination with MRSA. A total of 149 strains isolated from 2004 to 2010 within LEMA (Laboratorio de Ecología Microbiana y de Alimentos. Bogotá, Colombia) were analyzed.

Control strains. Meticillin-susceptible S. aureus (MSSA) ATCC 29213 and MRSA ATCC 33591 strains were used as positive controls in susceptibility test. MRSA USA 300 and Chilean clone NCTC 8325 were used as PFGE positive controls.

2.1. Bacterial isolation. For staphylococci isolation, 10 $\mathrm{g} / \mathrm{mL}$ of each sample were transfered to flasks with 90 $\mathrm{mL}$ of Peptone Water and then plated onto Baird Parker Agar (Scharlau, Spain). The samples were incubated at $35 \pm 2{ }^{\circ} \mathrm{C}$ for $48 \mathrm{~h}[19,20]$.

2.2. Antimicrobial susceptibility testing. Tests for Oxacillin and Cefoxitin resistance were carried out using the Kirby-Bauer disc diffusion method. McFarland 0.5 suspension was spotted onto Mueller-Hinton agar (MHA) (Becton Dickinson). The concentration of cefoxitin and oxacillin used was $30 \mu \mathrm{g}$ and $1 \mu \mathrm{g}$ (BBLTM, USA) respectively [21, 22].

2.3. Identification of $n u c$ and mecA genes. In order to confirm $S$. aureus species and mecA presence, PCR were performed amplifying nuc, mecA and $16 S$ rRNA (internal control) genes with primers previously described [23-25]. The mixture reaction for mecA consisted of $5.0 \mu \mathrm{l}$ of template DNA, $0.2 \mu \mathrm{M}$ of each primer, $2.0 \mathrm{mM}$ MgCL2, $160 \mu \mathrm{M}$ dNTPs, $1 \mathrm{X}$ buffer and $0.5 \mathrm{U}$ Taq Polymerase (Invitrogen) in a final volume of $25 \mu \mathrm{L}$. The reaction mixtures were subjected to $95^{\circ} \mathrm{C}$ for $3 \mathrm{~min}$ and then 30 cycles of $95^{\circ} \mathrm{C}$ for $10 \mathrm{~s}, 55^{\circ} \mathrm{C}$ for $30 \mathrm{~s}$ and $72^{\circ} \mathrm{C}$ for $30 \mathrm{~s}$, in an MJ Mini Thermocycler (Bio-Rad Laboratories, Inc. USA). PCR amplification products were separated on a $1.5 \%$ agarose gel and visualized under UV light by the addition of ethidium bromide using Quantity One software (Bio-Rad).

2.4. DNA Preparation, digestion, and PFGE. The preparation of the chromosomal DNA of MRSA isolates and digestion of their genomic DNA with SmaI (Promega) were performed as described by Cruz et al. [26]. Electrophoresis was performed with a CHEF-DR II system (Bio-Rad Laboratories, Hercules, CA) with the following conditions: block 1: run time $10 \mathrm{~h}$, switch time 5-15 s and voltage $6 \mathrm{~V} / \mathrm{cm}$; and block 2: run time $13 \mathrm{~h}$, switch time $15-60 \mathrm{~s}$ and voltage $6 \mathrm{~V} / \mathrm{cm}$. The gels were stained and photographed using Quantity One software (Bio-Rad). Cluster analysis of SmaI macrorestriction profiles was performed and analyzed using the Dice similarity coefficient with a PFGE band similarity software (GelComparII software; Bio-Rad 
Laboratories, Hercules, CA), using a cut-off of $85 \%$ as the criterion for cluster formation.

2.5. Antimicrobial Susceptibility test (AST). AST was performed only on the 5 MRSA strains identified thanks to the previously described methodologies, using the Phoenix AST method according to previously described techniques $[14,27]$. The Phoenix AST broth was briefly supplemented by one drop of Phoenix AST indicator. From the standardized ID microbial suspension, $25 \mathrm{~mL}$ was transferred to the AST broth. The broth was then poured into the AST side of the panel for specific detection of Staphylococcus penicillinase and extended-spectrum beta-lactamase (ESBL).

2.6. Identification of Toxin A gene. The PCR reactions were carried out using $240 \mathrm{ng}$ of genomic DNA extracted from the mecA positive strains [28]. All the amplifications were carried out in a thermal cycler Biorad PCR System, with initial denaturation at $94^{\circ} \mathrm{C}$ for 4 min followed by 30 cycles of denaturation at $94^{\circ} \mathrm{C}$ for $2 \mathrm{~min}$, primer annealing at $55^{\circ} \mathrm{C}$ for $2 \mathrm{~min}$ and extension at $55^{\circ} \mathrm{C}$ for $2 \mathrm{~min}$, followed by a final extension at $72^{\circ} \mathrm{C}$ for $7 \mathrm{~min}$ [29-31]. The amplified PCR products were visualized using standard gel electrophoresis in a $2 \%$ agarose gel, stained with ethidium bromide $(0.05 \mathrm{mg} / \mathrm{ml}$; Sigma Aldrich, Milan, Italy).

\section{Results}

Methicillin resistant $S$. aureus isolation from food products was performed as a preliminary test for the detection of the incidence of this food borne pathogen in
Colombia. Table 1 summarizes the results obtained with the disk diffusion method, mecA and Toxin $A$ gene amplification, and PFGE. $10(6.71 \%)$ of 149 presumptive $S$. aureus strains analyzed, were oxacillin and cefoxitin resistant, using an interpretive zone diameter of $\mathrm{R}<10 \mathrm{~mm}$. to oxacillin and $\mathrm{R}<19 \mathrm{~mm}$ to cefoxitin [32-34].

Of the 149 presumptive S. aureus, 5 (3.35\%) harbored nuc and mecA gene (Figure 1), four of them were isolated from ground beef (STA294, STA295, STA296, STA 297) and one strain from milk cream (STA54C).

The genomic DNA typing showed patterns of at least 9 fragments of $36.0674 \mathrm{~kb}$ in total in 5 MRSA isolates (Fig. 2). 4 of the 5 MRSA isolates showed a distinguishable banding PFGE pattern that match with the Chilean clone, with a $100 \%$ of genetic similarity. One isolate had a unique pattern not related to control clones.

All isolates with a mecA amplification (5 strains) were resistant to cefazolin, clindamycin, gentamicin, mupirocin high level, teicoplanin, trimethoprimsulfamethoxazole, vancomicin, oxacilin and cefoxitin. STA 294 and STA 295 isolated from beef were also resistant to amoxicillin-clavulanate, ampicillin, ciprofloxacin, erythromycin and levofloxacine.

In respect to the enterotoxin $\mathrm{A}$, the absence of the target staphylococcal toxin A gene strains was determined by the PCR for all of the mecA positive strains (5 isolates) tested in this study.

Table 1. Characterization of $S$. aureus isolates by presence of the $m e c A$ gene, disk diffusion method of cefoxitin and oxacillin, PFGE and Toxin A gene amplification.

\begin{tabular}{|c|c|c|c|c|c|c|c|}
\hline \multirow{2}{*}{ STRAIN } & \multirow{2}{*}{$\begin{array}{c}\text { DATE OF } \\
\text { ISOLATION }\end{array}$} & \multirow{2}{*}{ FOOD } & \multicolumn{2}{|c|}{ Inhibition zone (mm) } & \multirow{2}{*}{ mecA gene } & \multirow{2}{*}{$\begin{array}{c}\text { Chilean } \\
\text { Clone }\end{array}$} & \multirow{2}{*}{$\begin{array}{c}\text { Toxin A } \\
\text { gene }\end{array}$} \\
\hline & & & Cefoxitin & Oxacilin & & & \\
\hline STA 010 & $\begin{array}{c}\text { Donation } \\
\text { Universidad } \\
\text { Javeriana } \\
\end{array}$ & - & $0 \mathrm{~mm}$ & $0 \mathrm{~mm}$ & - & Not tested & Not tested \\
\hline STA105 & 8/07/04 & Milk cream & $0 \mathrm{~mm}$ & $0 \mathrm{~mm}$ & + & - & - \\
\hline $\begin{array}{l}\text { STA } \\
54 C \\
\end{array}$ & 8/07/04 & Milk cream & $0 \mathrm{~mm}$ & $0 \mathrm{~mm}$ & - & Not tested & Not tested \\
\hline STA 108 & $19 / 07 / 04$ & Fruit salad & $0 \mathrm{~mm}$ & $0 \mathrm{~mm}$ & - & Not tested & Not tested \\
\hline STA126 & $21 / 07 / 04$ & Fruit salad & $0 \mathrm{~mm}$ & $0 \mathrm{~mm}$ & - & Not tested & Not tested \\
\hline STA112 & $19 / 07 / 04$ & Fruit salad & $0 \mathrm{~mm}$ & $0 \mathrm{~mm}$ & - & Not tested & Not tested \\
\hline STA294 & $2 / 10$ & Ground beef & $0 \mathrm{~mm}$ & $0 \mathrm{~mm}$ & + & + & - \\
\hline STA295 & $2 / 10$ & Ground beef & $0 \mathrm{~mm}$ & $0 \mathrm{~mm}$ & + & + & - \\
\hline STA296 & $2 / 10$ & Ground beef & $\mathrm{Omm}$ & $0 \mathrm{~mm}$ & + & + & - \\
\hline STA297 & $2 / 10$ & Ground beef & $0 \mathrm{~mm}$ & $0 \mathrm{~mm}$ & + & + & - \\
\hline
\end{tabular}




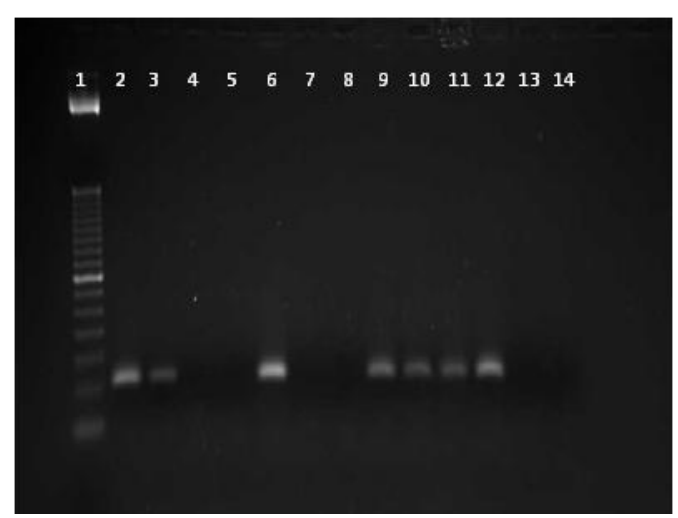

Fig. 1. Agarose gel electrophoresis for the detection of mecA gen .1: molecular weight marker (DNA Ladder 50 bp. BioRad). 2-3: Positive control Strains. 4: STA010. 5: STA108. 6: STA105. 7: 73SAUR. 8: 59SAUR. 9:STA294. 10: STA295. 11:STA296. 12: STA297. 13: STA54C. 14: PCR without DNA.

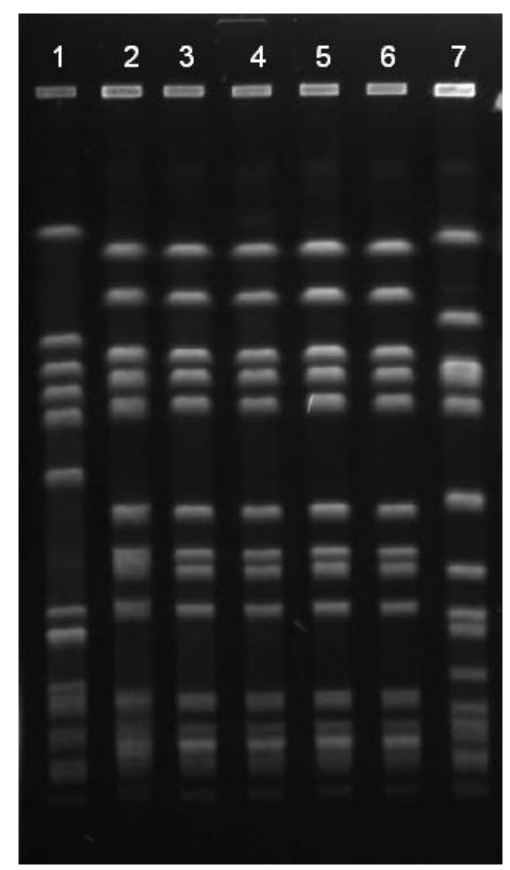

Fig. 2. PFGE for the detection of MRSA strains clonal groups 1: Positive control- USA300 Clone. 2: Positive control- Chilean Clone. 3-7: Food isolated strains STA294, STA295, STA296, STA297, STA105.

\section{Discussion}

Detection of the mecA gene is considered the gold standard for MRSA confirmation [35]. However, phenotypic methods like oxacillin and cefoxitin disc diffusion are now an accepted method for the detection of MRSA by many reference groups including CLSI [16,
36]. However there are difficulties associated with this method, as other species of Staphylococcus genus can test positive. Therefore it is still necessary to confirm the specie previously. The diameter of the inhibition area may be affected by the concentration of inoculums, MHA composition, temperature, and duration of incubation and occasionally some mecA positive strains are not detected due to the low expression of resistance [37].

In this study, results of the cefoxitin and oxacillin disc diffusion test are in concordance with the PCR for mecA gene. Even only half of the tested strains amplified $m e c A$ gene, the remaining strains did not amplify for $n u c$ gene, indicating that they were not $S$. aureus and then they should not amplify for the staphylococcal chromosome cassette (SCC). This findings agrees with the statement by KB Anand in 2009 [38], who argued that the diffusion method is very suitable for the detection of MRSA, and the test can be an alternative to PCR for detection of MRSA in settings characterized by resource constraints.

In this survey of 149 strains, 5 (3.0\%) were methicillin resistant (MRSA) percentage which is according to that stated by Normanno in 2007, who found that $3.75 \%$ of $160 \mathrm{~S}$. aureus strains isolated from food were MRSA harboring the mecA gene [1]. In another study Lee [39, 40] found $15(0.78 \%)$ of 1913 strains harboring the mecA gene. Most of the MRSA isolates found by the authors in this study, were from milk and cattle, which supports our findings with respect to MRSA isolation origin (Table 1). The source of food contamination is unclear since previous available reports are few and this is the first report about the presence of MRSA in Colombian foods.

The first molecular characterization of MRSA in Colombia was performed with clinical isolates recovered between 1996 and 1998; their results revealed that almost all of MRSA isolates belonged to a pediatric clone [5]. However, later studies observed that isolates with the characteristics of CA-MRSA strains increased in prevalence in Colombia between 2001 and 2006, belonging to the Chilean clone [26, 41]. Our findings suggest the presence of the same clone in food samples, showing MRSA's ability to disperse.

Suggested explanations for this phenomenon included the increased migration of human populations, combined with ineffective practices to control the spread of MRSA from infected or colonized patients [41]. Nevertheless, the prevalence of MRSA largely depends on the region and site of infection [42]. However, this study has demonstrated that MRSA has entered the food chain through the presence of MRSA in meat products 
in Colombia.

The antibiotics profile showed multiple antibioticresistances in all MRSA strains, which is important given that $S$. aureus is a common cause of nosocomial infections and a frequent cause of community-acquired infections [32]. Furthermore, these infections are commonly treated using beta-lactam antibiotics, and $S$. aureus had developed marked resistance to this [32]. Contamination of food products should be traced in order to identify potential threats of MRSA acquisition by consumers.

According to Normanno [1], MRSA strains are able to synthesize different kinds of enterotoxins alone or in association, providing further evidence that MRSA may also be involved in food poisoning outbreaks.

The identification of staphylococcal toxin $A$ gene in $S$. aureus strains by PCR offers a very specific, sensitive and inexpensive alternative to traditional immunological assays, which depend on adequate gene expression for reliability and sensitivity. The absence of the target staphylococcal toxin $A$ gene strains was determined by the PCR for all of the mecA positive strains (5 isolates) tested in this study. However it does not mean that Staphylococcical toxins were absent, because it is necessary to evaluate them for all other known enterotoxin genes seB to seI [43].

These findings are important because they show the incidence of MRSA in Colombia and are the first to be shown in the country. It is necessary to continue this research by extending sampling and collecting enough information to carry out a risk analysis of this danger and for the epidemiological control of this pathogen.

\section{References}

[1] Normanno, G., et al., Methicillin-resistant Staphylococcus aureus (MRSA) in foods of animal origin product in Italy. Int J Food Microbiol, 2007. 117(2): p. 219-22.

http://dx.doi.org/10.1016/j.ijfoodmicro.2007.04.006

[2] Boucher, H.W. and G.R. Corey, Epidemiology of Methicillin-Resistant Staphylococcus aureus. Clinical Infectious Diseases, 2008. 46(Supplement 5): p. S344-S349. http://dx.doi.org/10.1086/533590

[3] Pu, S., F. Han, and B. Ge, Isolation and characterization of methicillin-resistant Staphylococcus aureus strains from Louisiana retail meats. Appl Environ Microbiol, 2009. 75(1): p. 265-7. http://dx.doi.org/10.1128/AEM.01110-08

[4] Jarvis, W.R., Prevention and control of methicillin-resistant Staphylococcus aureus: dealing with reality, resistance, and resistance to reality. Clin Infect Dis, 2010. 50(2): p. 218-20. http://dx.doi.org/10.1086/648718

[5] Manuel, G.-B., et al., Epidemiology of meticillin-resistant Staphylococcus aureus (MRSA) in Latin America. International journal of antimicrobial agents, 2009. 34(4): p. 304-308. http://dx.doi.org/10.1016/j.ijantimicag.2009.06.005

[6] Normanno, G., et al., Coagulase-positive Staphylococci and Staphylococcus aureus in food products marketed in Italy. International Journal of Food Microbiology, 2005. 98(1): p. 73-79. http://dx.doi.org/10.1016/j.ijfoodmicro.2004.05.008

[7] Normanno, G., et al., Occurrence, characterization and antimicrobial resistance of enterotoxigenic Staphylococcus aureus isolated from meat and dairy products. Int J Food Microbiol, 2007. 115(3): p. 290-6.

http://dx.doi.org/10.1016/j.ijfoodmicro.2006.10.049

[8] Mathur, S. and R. Singh, Antibiotic resistance in food lactic acid bacteria--a review. Int J Food Microbiol, 2005. 105(3): p. 281-95. http://dx.doi.org/10.1016/j.ijfoodmicro.2005.03.008

[9] Angulo, F.J., V.N. Nargund, and T.C. Chiller, Evidence of an Association Between Use of Anti-microbial Agents in Food Animals and Anti-microbial Resistance Among Bacteria Isolated from Humans and the Human Health Consequences of Such Resistance. Journal of Veterinary Medicine, Series B, 2004. 51(8-9): p. 374-379. http://dx.doi.org/10.1111/j.1439-0450.2004.00789.x

[10] Fuda, C., et al., The Basis for Resistance to $\beta$-Lactam Antibiotics by Penicillin-binding Protein 2 a of Methicillin-resistant Staphylococcus aureus. Journal of Biological Chemistry, 2004. 279(39): p. 40802-40806. http://dx.doi.org/10.1074/jbc.M403589200

[11] Lemaire, S., et al., Restoration of Susceptibility of Methicillin-resistant Staphylococcus aureus to $\beta$-Lactam Antibiotics by Acidic $p H$. Journal of Biological Chemistry, 2008. 283(19): p. 12769-12776. http://dx.doi.org/10.1074/jbc.M800079200

[12] Leticia I. Llarrull, J.F.F., and Shahriar Mobashery, Molecular Basis and Phenotype of Methicillin Resistance in Staphylococcus aureus and Insights into New -Lactams That Meet the Challenge Antimicrobial Agents and Chemotheraphy 2009. 53(10): p. 4051-4063.

[13] Pfaller, M.A., et al., Survey of blood stream infections attributable to gram-positive cocci: frequency of occurrence and antimicrobial susceptibility of isolates collected in 1997 in the United States, Canada, and Latin America from the 
SENTRY Antimicrobial Surveillance Program. SENTRY Participants Group. Diagn Microbiol Infect Dis, 1999. 33(4): p. 283-97. http://dx.doi.org/10.1016/S0732-8893(98)00149-7

[14] Schmitz, F.-J., et al., Enterotoxin and toxic shock syndrome toxin-1 production of methicillin resistant and methicillin sensitive Staphylococcus aureus strains. European Journal of Epidemiology, 1997. 13(6): p. 699-708. http://dx.doi.org/10.1023/A:1007357206672

[15] Bécquer, e.a., Obtención de antisueros para las enterotoxinas estafilocócicas A y $C$. Rev Cubana Aliment Nutr, 1990. 4:270-5.: p. 270 - 275.

[16] Skov, R., et al., Evaluation of a cefoxitin $30 \mu \mathrm{g}$ disc on Iso-Sensitest agar for detection of methicillin-resistant Staphylococcus aureus. Journal of Antimicrobial Chemotherapy, 2003. 52(2): p. 204-207. http://dx.doi.org/10.1093/jac/dkg325

[17] Enright, M.C., et al., Multilocus Sequence Typing for Characterization of Methicillin-Resistant and Methicillin-Susceptible Clones of Staphylococcus aureus. J. Clin. Microbiol., 2000. 38(3): p. 1008-1015.

[18] Oliveira, D.C., A. Tomasz, and H. de Lencastre, Secrets of success of a human pathogen: molecular evolution of pandemic clones of meticillin-resistant Staphylococcus aureus. The Lancet Infectious

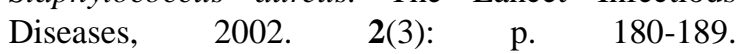
http://dx.doi.org/10.1016/S1473-3099(02)00227-X

[19] Kennedy, A.D., et al., Epidemic community-associated methicillin-resistant Staphylococcus aureus: Recent clonal expansion and diversification. Proceedings of the National Academy of Sciences, 2008. 105(4): p. 1327-1332. http://dx.doi.org/10.1073/pnas.0710217105

[20] Pu, S., F. Han, and B. Ge, Isolation and Characterization of Methicillin-Resistant Staphylococcus aureus Strains from Louisiana Retail Meats. Appl. Environ. Microbiol., 2009. 75(1): p. 265-267. http://dx.doi.org/10.1128/AEM.01110-08

[21] Ikonomidis, A., et al., In Vitro and In Vivo Evaluations of Oxacillin Efficiency against mecA-Positive Oxacillin-Susceptible Staphylococcus aureus. Antimicrob. Agents Chemother., 2008. 52(11): p. 3905-3908.

http://dx.doi.org/10.1128/AAC.00653-08

[22] B. Cauwelier, B.G., P. Descheemaecker and H. Van Landuyt, Evaluation of a disk diffusion method with cefoxitin $(30 \quad \mu g)$ for detection of methicillin-resistant Staphylococcus aureus. European Journal of Clinical Microbiology and
Infectious Diseases, 2004. 23(5): p. 389-392.

[23] Martineau, F., et al., Correlation between the Resistance Genotype Determined by Multiplex PCR Assays and the Antibiotic Susceptibility Patterns of Staphylococcus aureus and Staphylococcus epidermidis. Antimicrob. Agents Chemother., 2000. 44(2): p. 231-238.

http://dx.doi.org/10.1128/AAC.44.2.231-238.2000

[24] Stuhlmeier, R.S.a.K.M., Fast, simultaneous, and sensitive detection of staphylococci. Journal of Clinical Pathology, 2003. 56(10): p. 782-785. http://dx.doi.org/10.1136/jcp.56.10.782

[25] Dojka, M.A., J.K. Harris, and N.R. Pace, Expanding the Known Diversity and Environmental Distribution of an Uncultured Phylogenetic Division of Bacteria. Applied and Environmental Microbiology, 2000. 66(4): p. 1617-1621. http://dx.doi.org/10.1128/AEM.66.4.1617-1621.2000

[26] Cruz, C., et al., Tracking methicillin-resistant Staphylococcus aureus clones in Colombian hospitals over 7 years (1996-2003): emergence of a new dominant clone. Int J Antimicrob Agents, 2005. 26(6): p. 457-62.

http://dx.doi.org/10.1016/j.ijantimicag.2005.08.013

[27] Fahr, A.M., et al., Two-center collaborative evaluation of the performance of the BD Phoenix automated microbiology system for identification and antimicrobial susceptibility testing of Enterococcus spp. and Staphylococcus spp. J Clin Microbiol, 2003. 41(3): p. 1135-42. http://dx.doi.org/10.1128/JCM.41.3.1135-1142.2003

[28] Brown, D.F., et al., Guidelines for the laboratory diagnosis and susceptibility testing of methicillin-resistant Staphylococcus aureus (MRSA). J Antimicrob Chemother, 2005. 56(6): p. 1000-18. http://dx.doi.org/10.1093/jac/dki372

[29] Brisse, S., et al., Comparative evaluation of the BD Phoenix and VITEK 2 automated instruments for identification of isolates of the Burkholderia cepacia complex. J Clin Microbiol, 2002. 40(5): p. 1743-8. http://dx.doi.org/10.1128/JCM.40.5.1743-1748.2002

[30] McLauchlin, J., et al., The Detection of Enterotoxins and Toxic Shock Syndrome Toxin Genes in Staphylococcus aureus by Polymerase Chain Reaction. Journal of Food Protection, 2000. 63(4): p. 479-488.

[31] Vanegas L, M., et al., AISLAMIENTO $Y$ CARACTERIZACIÓN DE CEPAS DE Staphylococcus ENTEROTOXIGÉNICOS AISLADOS DE QUESOS EN BOGOTA. Revista MVZ Córdoba, 2008. 13: p. 1288-1293. 
[32] (CDC), C.f.D.C.a.P., Reduced susceptibility of Staphylococcus aureus to vancomycin--Japan, 1996, in MMWR Morb Mortal Wkly Rep1997. p. 624-6.

[33] Institute, C.a.L.S., Performance standards for antimicrobial susceptibility testing, 2005: Wayne, $\mathrm{Pa}$, USA.

[34] Mimica, M.J., et al., Detection of methicillin resistance in Staphylococcus aureus isolated from pediatric patients: is the cefoxitin disk diffusion test accurate enough? Brazilian Journal of Infectious Diseases, 2007. 11: p. 415-417. http://dx.doi.org/10.1590/S1413-86702007000400009

[35] Skov, R., et al., Phenotypic detection of methicillin resistance in Staphylococcus aureus by disk diffusion testing and Etest on Mueller-Hinton agar. J Clin Microbiol, 2006. 44(12): p. 4395-9. http://dx.doi.org/10.1128/JCM.01411-06

[36] Standards, N.C.f.C.L., Performance Standards for Antimicrobial Disk Susceptibility Tests, 2000: Villanova, PA, USA.

[37] Fernandes, C.J., et al., Cefoxitin resistance as a surrogate marker for the detection of methicillin-resistant Staphylococcus aureus. Journal of Antimicrobial Chemotherapy, 2005. 55(4): p. 506-510. http://dx.doi.org/10.1093/jac/dki052

[38] Anand, K.B., et al., Comparison of cefoxitin disc diffusion test, oxacillin screen agar, and PCR for mecA gene for detection of MRSA. Indian $\mathrm{J} \mathrm{Med}$
Microbiol, 2009. 27(1): p. 27-9.

[39] Lee, J.H., Methicillin (Oxacillin)-Resistant Staphylococcus aureus Strains Isolated from Major Food Animals and Their Potential Transmission to Humans. Appl. Environ. Microbiol., 2003. 69(11): p. 6489-6494.

http://dx.doi.org/10.1128/AEM.69.11.6489-6494.2003

[40] Lee, J.H., Occurrence of methicillin-resistant Staphylococcus aureus strains from cattle and chicken, and analyses of their mecA, mecRl and mecI genes. Vet Microbiol, 2006. 114(1-2): p. 155-9. http://dx.doi.org/10.1016/j.vetmic.2005.10.024

[41] Rodriguez-Noriega, E., et al., Evolution of methicillin-resistant Staphylococcus aureus clones in Latin America. Int J Infect Dis, 2010. 14(7): p. e560-6. http://dx.doi.org/10.1016/j.ijid.2009.08.018

[42] Pesavento, G., et al., Antimicrobial resistance profile of Staphylococcus aureus isolated from raw meat: A research for methicillin resistant Staphylococcus aureus (MRSA). Food Control, 2007. 18(3): p. 196-200. http://dx.doi.org/10.1016/j.foodcont.2005.09.013

[43] Gutierrez A., G., Revollo Z., Susana, Espada, Angélica et al. , Identificación mediante PCR del gen codificador de la enterotoxina de Staphylococcus aureus en productos lácteos. Visión científica, 2009. 1: p. 56-59. 